\title{
Relationships between Demographic Variables and Breast Self-Examination among Women in a Rural Community South East of Nigeria
}

\author{
Ada C. Nwaneri1 ${ }^{1}$ Eunice Ogonna Osuala ${ }^{2 *}$, Ijeoma Okoronkwo', Patricia Uzor Okpala1, \\ Anthonia Chidinma Emesowum ${ }^{3}$ \\ ${ }^{1}$ Department of Nursing, University of Nigeria, Enugu Campus, Nsukka, Nigeria \\ ${ }^{2}$ Department of Nursing Science, Nnamdi Azikiwe University, Nnewi Campus, Awka, Nigeria \\ ${ }^{3}$ Department of Nursing, Imo State University, Orlu Campus, Owerri, Nigeria \\ Email: *euniceosuala@yahoo.com
}

Received 24 August 2015; accepted 22 January 2016; published 25 January 2016

Copyright (C) 2016 by authors and Scientific Research Publishing Inc.

This work is licensed under the Creative Commons Attribution International License (CC BY).

http://creativecommons.org/licenses/by/4.0/

(c) (i) Open Access

\begin{abstract}
This study examined the relationships between demographic variables of women in a rural community, South East of Nigeria and their practice of Breast Self-Examination (BSE). A descriptive survey design was adopted. The study population of 349 was drawn using system atichousehold sampling technique. Two research questions and three null hypotheses guided the study. The instruments used for data collection were validated structured questionnaire which was interview administered. Demographic information of the women such was also obtained for the study. The result indicated significant correlation between respondents' educational level and BSE. There was however no significance difference between age, parity and BSE. There was need for community health nurses to reinforce home visits in order to enhance the awareness of breast cancer and needed skill for BSE among the rural populace while liberal education irrespective of age should be instituted by the Government.
\end{abstract}

\section{Keywords}

Demographic Variables, Breast Self-Examination, Rural-Women

\footnotetext{
${ }^{*}$ Corresponding author.
}

How to cite this paper: Nwaneri, A.C., Osuala, E.O., Okoronkwo, I., Okpala, P.U. and Emesowum, A.C. (2016) Relationships between Demographic Variables and Breast Self-Examination among Women in a Rural Community South East of Nigeria. Health, 8, 98-104. http://dx.doi.org/10.4236/health.2016.81012 


\section{Introduction}

Breast cancer is the commonest cancer and remains the most lethal malignancy in women across the world [1]. It constitutes a major public health issue globally with over one million new cases diagnosed annually, resulting in over 400,000 annual deaths and about 4.4 million women living with the disease [2] [3]. In Nigeria, the number of women at risk of breast cancer increased steadily from approximately 24.5 million in 1900 to approximately 40 million in 2010 and is projected to rise to over 50 million by 2020 [4]. Statistics from the Ministry of Health Nigeria shows that breast cancer has risen at least four times over the decade and has accounted for 40 percent of women cancers [5]. In the present scenario, roughly 1 in 26 women is expected to be diagnosed with breast cancer in their life time, majority of cases occurring in pre-menopausal women [1]. Following hospital records in Nigeria, breast cancer is truly an epidemic among women as it is estimated that 211,000 new cases of invasive breast cancer are diagnosed in a year, and 43,000 patients died of the disease [6].

The high mortality reported on breast cancer is as a result of late presentation at advanced stage with poorer clinical and pathological prognostic outcome. With early detection, five year survival rate of over $85 \%$ is achieved whereas late detection decreases the survival rate to 5\% (1: 4). The low survival rates of breast cancer in less developed countries can be attributed to lack of early detection as well as inadequate diagnosis and treatment facilities. Chiejina [7] notes that what is more worrisome in a country like Nigeria with over 140 million people is that the detection of the disease is usually late. For women to present early, they must be able to recognize symptoms of breast cancer through routine practice. BSE may be influenced by awareness of breast cancer, some demographic variables as age and parity as well as the skill for breast examination. Descriptive survey design with the aid of a questionnaire is served as an interview schedule for the study on 349 women in Umuowa, Orlu L.G.A of Imo State. The objective of this study is to find out if there exists relationships between age, educational level, parity of rural women and their practice of Breast Self-Examination. Findings will guide future intervention in scaling up BSE in the community. The study is guided by four research questions and three hypotheses.

\section{Research Questions}

- How do the women of Umuowa Orlu LGA practice BSE?

- How does demographic variable of age, academic attainment and parity of respondents relate to practice of BSE?

\section{Hypotheses}

- There is no significant relationship between the age of respondents and their BSE practice.

- There is no significant relationship between the educational attainment of respondents and their BSE practice.

- There is no significant relationship between the parity of respondents and their BSE practice.

\section{Materials and Methods}

\subsection{Design and Sampling}

This is a descriptive survey design conducted among 349 women (Ages 20-70) from a rural community in the South East of Nigeria from 3rd to 28th February 2015. The sample was drawn from a target population [8] of 3820 using Krejcie and Morgan [9] power analysis formular $\left(S=X^{2} N P(1-P) / d^{2}(N-1)\right.$. Systematic sampling technique was used to pick the required households. The sampling interval was every 11th household. The women in each of the selected households that met the inclusion criteria (aged between 20 and 70, single or married, residing in the community for a minimum of one year) were included in the study based on their willingness.

\section{Instrument}

Instrument for data collection was a questionnaire formulated by researchers based on the objective of the study. Questionnaire was validated through experts in the field of Gynacology, Measurement and Evaluation and Community Health Nursing. Back translation from English to Igbo language was done by higher school teachers 
in English and Igbo (Local) languages respectively for congruency. The instrument consisted of two major sections A and B. Section A contains the demographic characteristics while section B had questions on practice. A pilot study on 40 women from another community with same characteristics was done. Coefficient correlation of 0.78 was computed on a test-retest of the instrument. Same was interview administered by three nurses. The exercise was on daily basis and the interview was on one on one lasting for 10 minutes per participant. The literate ones were interviewed in English while the non literate were interviewed in Igbo. Research question was answered using responses to questions 19 to 27 of the research instrument which extracted responses on frequency, procedure and observations made. The questionnaire which was interview administered was filled for every woman, in the 11th household, who is within the age limit and gave consent to participate, until the required sample was got. Data was collected after obtaining ethical approval from the ethical committee of the University of Nigeria Teaching Hospital, Enugu, Nigeria.

\section{Data Analysis}

Research questions were answered using responses to questions 19 to 27 of the research instrument which extracted information on breast self examination. The 4 questions on frequency and 1 on observation had a maximum score of 8 and 3 respectively while the 4 questions on procedure had a maximum score of 8 . Composite score was computed after summation of scores per participant. The responses were scored over 19, and rated as follows:

Scores $\leq 6$

Scores from 7 to 12

Scores from 13 to 19

Inadequate practice

Descriptive and inferential analysis was carried out using Social Package for Social Sciences version 18. Mean score, standard deviation (SD) Pearson's Correlation Coefficient (R), and Spearman Rank Correlation Coefficient (rho) were used to answer the research questions while Chi-square, was adopted in testing the null hypotheses at 0.05 level of significance.

\section{Results}

\subsection{Demographic Characteristics}

The respondents that were within the age range of (20 - 30) constituted 30.1\% while those that were within the ages 51 - 60 were the least in number 38 (10.5\%). Mean age of respondents was $42 \pm 10.7$. Majority of the respondents, 183 (52.41\%) were married while 88 (25.2\%) were single. One hundred and twenty nine (37.0\%) had tertiary education and only 15 (4.3\%) had no formal education. Ninety-six (27.5\%) were civil servants while 52 (14.9\%), 46 (13.2\%) and 39 (11.2\%) were farmers, traders and business women. One hundred and two (29.2\%) of the women are primigravida, 53 (15.2\%) have one child each while 108 (31\%), 52 (15\%) and 34 (10\%) have 2 - 3, 4 - 5 and 6 or more children respectively (Table 1).

\subsection{Practice of BSE}

\subsubsection{Frequency, Timing, Method and Barriers}

Findings on practice showed that $50.1 \%$ of participants had inadequate level of practice, $33.5 \%$ moderately inadequate and $16.3 \%$ are highly adequate in practice. Responses on practice showed that one hundred and eighty one (51.9\%) respondents have performed BSE while 168 (48.1\%) respondents have not. Out of the 181 respondents that had performed BSE, 32 (17.7\%) said they performed it once a month, 27 (16.0\%) performed it once in two months, 19 (10.4\%) performed it once in three months, 94 (51.9\%) performed BSE anytime that was convenient while 9 (5.0\%) respondents said they do not know how often they performed the examination. Concerning the timing of BSE, 24 (13.3\%) respondents said they performed BSE 2nd to 3rd day after menstruation. 53 (27.3\%) performed it 2nd to 3rd day before menstruation, 10 (5.5\%) examined the breast during ovulation while 94 (51.9\%) did not have any specific time for performing BSE. Reasons for not performing BSE were also sought. Out of the 168 respondents that have not performed BSE, 8 (4.4\%) respondents gave their reason as lack of confidence on how to do it, 105 (62.4\%) the respondents said it was because they were not sure of their ability to detect breast changes. 5 (3.0\%) said it was because they found the process BSE difficult to remember. 40 (23.8\%) respondents had no time while 10 (6.0\%) respondents said it was because they had no family history of 
breast cancer and do not see the need. None of respondents found BSE embarrassing, for BSE (Table 1). Assessment of the steps that the participants' follow when performing BSE showed that 36 (19.9\%) respondents examined the breasts in front of a mirror with breast and chest (top) exposed, while 145 (80.1\%) respondents did not. 35 (19.3\%) respondents noted that they checked for dimpling, swelling, soreness, in all parts of the breast in front of the mirror while 146 (80.7\%) did not. 45 (24.9\%) respondents changed position to look at the different parts of the breast while 136 (75.1\%) did not. 65 (35.9\%) respondents said they looked for dimpling, swelling, soreness in all parts of the breast in the mirror with arm raised while $116(64.1 \%)$ respondents deferred on this (Table 2).

Table 1. Demographic characteristics of respondents $n=349$.

\begin{tabular}{|c|c|c|c|}
\hline & & Frequency & Percent (\%) \\
\hline \multirow{6}{*}{ Age } & $20-30$ & 105 & 30.1 \\
\hline & $31-40$ & 67 & 19.2 \\
\hline & $41-50$ & 55 & 15.8 \\
\hline & $51-60$ & 38 & 10.9 \\
\hline & 61 and above & 84 & 24.1 \\
\hline & Total & 349 & 100.0 \\
\hline \multirow{6}{*}{ Marital Status } & Single & 88 & 25.2 \\
\hline & Married & 183 & 52.4 \\
\hline & Divorced & 16 & 4.6 \\
\hline & Widowed & 51 & 14.6 \\
\hline & Separated & 11 & 3.2 \\
\hline & Total & 349 & 100.0 \\
\hline \multirow{6}{*}{ Educational Qualification } & No formal education & 15 & 4.3 \\
\hline & Primary education & 79 & 22.6 \\
\hline & Secondary education & 121 & 34.7 \\
\hline & Tertiary education & 129 & 37.0 \\
\hline & Others & 5 & 1.4 \\
\hline & Total & 349 & 100.0 \\
\hline \multirow{6}{*}{ Parity } & None & 102 & 29.2 \\
\hline & 1 Only & 53 & 15.2 \\
\hline & $2-3$ & 108 & 30.9 \\
\hline & $4-5$ & 52 & 14.9 \\
\hline & 6 and above & 34 & 9.7 \\
\hline & Total & 349 & 100.0 \\
\hline
\end{tabular}

Table 2. Frequency of practice of BSE $n=181$.

\begin{tabular}{|c|c|c|}
\hline Question & Options & Freq. (\%) \\
\hline \multirow{2}{*}{$\begin{array}{l}\text { Have you ever performed breast } \\
\text { self examination? }\end{array}$} & Yes & $181(51.9)$ \\
\hline & No & $168(48.1)$ \\
\hline \multirow{5}{*}{$\begin{array}{l}\text { If yes, how often do you perform it? } \\
\qquad(\mathrm{n}=181)\end{array}$} & Once a month & $32(17.7)$ \\
\hline & Once in two months & $27(16.0)$ \\
\hline & Once in three months & $19(10.0)$ \\
\hline & Anytime is convenient & 94 (51.9) \\
\hline & Don't know how often & $9(17.7)$ \\
\hline \multirow{5}{*}{$\begin{array}{l}\text { At what time do you perform breast } \\
\text { self examination? } \\
\qquad(\mathrm{n}=181)\end{array}$} & 2nd-3rd day after menses & $24(13.3)$ \\
\hline & 2nd-3rd day before menses & $53(27.3)$ \\
\hline & during menses & $0(0.0)$ \\
\hline & during ovulation & $10(5.5)$ \\
\hline & no specific time & 94 (51.9) \\
\hline \multirow{6}{*}{$\begin{array}{l}\text { If you don't, what are your reasons } \\
\text { for not doing it? } \\
\qquad(n=168)\end{array}$} & Not confident on how to do it & $8(4.8)$ \\
\hline & Not sure of ability to detect breast changes & $105(62.4)$ \\
\hline & Find it difficult to remember & $5(3.0)$ \\
\hline & Find it embarrassing & $0(0.0)$ \\
\hline & Has no time & $40(23.8)$ \\
\hline & Has no family history of breast cancer and do not see the need for it & $10(6.0)$ \\
\hline
\end{tabular}




\subsubsection{Answers to Research Question on How the Demographic Variables Are Related to BSE Are Stated Below}

Table 3, showed that 44 (41.9\%) respondents aged 20 to 30, have inadequate practice of BSE while only 19 (18.1\%) have high adequate practice. Respondents aged 31 to 40, 20 (29.9\%), 24 (35.8\%) and 23 (34.3\%) inadequate, moderately adequate and highly adequate practice of BSE respectively. Respondents aged 41 to 50,13 (23.6\%), 30 (54.5\%) and 12 (5.3\%) inadequate, moderately adequate and highly adequate practice of BSE respectively. Those aged 51 to 60, 21 (53.3\%), 15 (39.5\%) and 2 (5.3\%) inadequate, moderately adequate and highly adequate practice of BSE. While respondents aged 61 and above, 77 (91.75\%), 6 (7.1\%) and 1 (1.2\%) had inadequate, moderately adequate and highly adequate practice of BSE. This showed respondents between 31 and 40 years old had more practice of BSE than the other age groups (as 34.3\% of them had high BSE practice) and respondents from 61 years old above had the least practice. With a Pearson's Correlation Coefficient (R) of -0.234 and a Spearman's Rank Correlation Coefficient (R) of -0.232 and a $p$-value of $0.000<0.05$, a correlation between age and practice of BSE was established. With the correlation coefficient being negative, the result showed that with increase in age, the practice of BSE reduced and vice versa. Thus, there was a negative relationship between age and the practice of BSE.

The results in Table 4 revealed that the 15 (100.0\%) of respondents with no formal education rated inadequate practice in BSE and none was rated moderately adequate or highly adequate practice. 78 (98.7\%) with primary education were rated inadequate practice of BSE, $1(1.3 \%)$ moderately adequate and none for highly adequate practice. Those with secondary education had 94 (77.7\%) for inadequate practice of BSE, 15 (12.4\%) moderately adequate practice of BSE and 12 (9.9\%) highly adequate practice of BSE. Respondents that had tertiary education had 48 (37.2\%) for inadequate practice of BSE, 28 (21.75) moderately adequate practice of BSE and $53(41.1 \%)$ highly adequate practice of BSE. Respondents with other qualifications had 1 (20.0\%) for inadequate practice of BSE. 2 (40.0\%) for both moderately adequate and highly adequate practice of BSE. Thus respondents with no formal education practiced BSE the least (as 100\% of them had low practice of BSE) while respondents with tertiary education practiced BSE the most (as $41.1 \%$ of them had high practice of BSE). With a Pearson's Correlation Coefficient (R) of 0.550 and a Spearman's Rank Correlation Coefficient (R) of 0.516 and a $p$-value of $0.000<0.05$, a correlation between educational attainment and practice of BSE is established. With the correlation coefficients being positive, the result showed that with increase in educational qualification, the

Table 3. Practice of BSE in relation to age.

\begin{tabular}{ccccc} 
& \multicolumn{3}{c}{ Practice of Breast Self-examination } & Total (\%) \\
\cline { 2 - 4 } Age Group & Inadequate (\%) & Moderately Adequate (\%) & $\begin{array}{c}\text { Highly Adequate } \\
\text { (\%) }\end{array}$ & \\
\hline $20-30$ & $44(41.9)$ & $42(40.0)$ & $19(18.1)$ & $105(100.0)$ \\
$31-40$ & $20(29.9)$ & $24(35.8)$ & $23(34.3)$ & $67(100.0)$ \\
$41-50$ & $13(23.6)$ & $30(54.5)$ & $12(21.8)$ & $55(100.0)$ \\
$51-60$ & $21(55.3)$ & $15(39.5)$ & $2(5.3)$ & $38(100.0)$ \\
61 and above & $77(91.7)$ & $6(7.1)$ & $1(1.2)$ & $84(100.0)$ \\
Total & $175(50.1)$ & $117(33.5)$ & $57(16.3)$ & $349(100.0)$ \\
\hline
\end{tabular}

Table 4. Cross-tabulation between Educational attainment and practice of BSE.

\begin{tabular}{|c|c|c|c|c|}
\hline \multirow[b]{2}{*}{ Educational Qualification } & \multicolumn{3}{|c|}{ Practice of BSE } & \multirow[b]{2}{*}{ Total (\%) } \\
\hline & Inadequate (\%) & $\begin{array}{c}\text { Moderately Adequate } \\
\text { (\%) }\end{array}$ & $\begin{array}{l}\text { Highly Adequate } \\
\text { (\%) }\end{array}$ & \\
\hline No formal education & $15(100.0)$ & $0(0.0)$ & $0(0.0)$ & $15(100.0)$ \\
\hline Primary education & $78(98.7)$ & $1(1.3)$ & $0(0.0)$ & $79(100.0)$ \\
\hline Secondary education & $94(77.7)$ & $15(12.4)$ & $12(9.9)$ & $121(100.0)$ \\
\hline Tertiary education & $48(37.2)$ & $28(21.7)$ & $53(41.1)$ & $129(100.0)$ \\
\hline Others & $1(20.0)$ & $2(40.0)$ & $2(40.0)$ & $5(100.0)$ \\
\hline Total & $236(67.6)$ & $46(13.2)$ & $67(19.2)$ & 349 (100.0) \\
\hline
\end{tabular}


practice of BSE increases and vice versa. This showed that the practice of BSE can be associated with the level of education.

Table 5 revealed that respondents with no child had 65 (63.7\%), 19 (18.6\%) and 18 (17.6\%) in adequate, moderately adequate and highly adequate practice of BSE respectively. Respondents with only one child had 33 (63.7\%), 9 (17.0\%) and 11 (20.85) inadequate, moderately adequate and highly adequate practice of BSE respectively. Those with 2 and three children had 69 (63.9\%), 14 (13.0\%) and 25 (23.1\%) for inadequate, moderately adequate and highly adequate practice of BSE respectively. Respondents with 4 and 5 children had 38 (73.1\%), 1 (1.9\%) and 13 (25.0\%) inadequate, moderately adequate and highly adequate practice of BSE respectively. This indicated that respondents with parity of 6 and above practiced BSE the least (as $91.2 \%$ of them had low practice of BSE) while respondents with parity of 4 to 5 practiced it the most (as $25 \%$ of them had high practice of BSE). Pearson's Correlation Coefficient (R) of -0.184 ( $p$-value of $0.001>0.05$ ) and a Spearman's Rank Correlation Coefficient (R) of -0.192 ( $p$-value of $0.039<0.05$ ) was established, showing that a correlation existed between parity and BSE practice. With the correlation coefficient being negative, the result showed that with increase in parity, the practice of BSE reduced and vice versa. Therefore, there was a negative relationship between parity and the practice of BSE.

\section{Hypotheses}

The three hypotheses on significant relationships between the demographic variables and BSE were computed using Chi-Square. For educational attainment Chi-Square value of 154.421 and $p$-value of $0.000<0.05$ showed that there was a significant relationship between level of education and practice of BSE. There was no significant relationship between age, parity and BSE as their $p$-value were $>0.05$

\section{Discussion}

A little more than half of the respondents claimed to have performed BSE. Majority of the respondents who performed BSE did not follow the correct steps for BSE. Half of the respondents reported that they have no specific time when performing BSE. A significant proportion of the respondents do not follow any pattern while performing BSE. The major reason for not practicing BSE was lack of confidence in the ability to detect breast changes. Generally, the practice of BSE was inadequate for majority of the participants. These may likely be among the factors that contribute to late detection of breast cancer as noted by Chiejina [7] coupled with limited information which is characteristic of a rural community [10]. There was a negative relationship between age and practice of breast self examination. This implies that with increase in age, the practice of BSE reduced. This may be due to lack of confidence or ignorant of the fact that cancer of the breast knows no age limit. Training on BSE and constant practice may promote self care and efficacy, thus health promotion programmes on behavior change should target the older ones. There was a positive relationship between educational attainment and practice of breast self-examination as in the study by Subramanian [11]; this showed that with increased educational level, the practice of BSE increased. This portrays the importance of education in scaling up practice. There was a negative relationship between parity and practice of breast self examination; this implied that with increased parity, the practice of BSE reduced. Some mothers may have thought that because they are having babies and no history of breast cancer in the family, they are immuned to breast cancer hence the apathy in practice among them. This misconception need to be corrected through Health Education for BSE to be promoted.

Table 5. Cross-tabulation between parity and practice of BSE.

\begin{tabular}{ccccc}
\hline & \multicolumn{4}{c}{ Practice of BSE } \\
Parity & Inadequate (\%) & Moderately adequate (\%) & Highly adequate (\%) & \\
\cline { 2 - 4 } & $65(63.7)$ & $19(18.6)$ & $18(17.6)$ & $102(100.0)$ \\
None & $33(62.3)$ & $9(17.0)$ & $11(20.8)$ & $53(100.0)$ \\
1 Only & $69(63.9)$ & $14(13.0)$ & $25(23.1)$ & $108(100.0)$ \\
$2-3$ & $38(73.1)$ & $1(1.9)$ & $13(25.0)$ & $52(100.0)$ \\
$4-5$ & $31(91.2)$ & $3(8.8)$ & $0(0.0)$ & $34(100.0)$ \\
and above & $236(67.6)$ & $46(13.2)$ & $67(19.2)$ & $349(100.0)$ \\
Total & & &
\end{tabular}




\section{Conclusion and Recommendation}

Only about half of the respondents have performed BSE yet majority of them do not follow the correct steps for BSE. The elderly women among them seem not to have seen the need for the test. Educational attainment is found to be positively related to BSE. Education should be made free and accessible to all women in the community irrespective of age to boost the practice of BSE in order to promote early detection and prevent untimely death among women sequel to breast cancer.

\section{References}

[1] Doshi, D., Reddy, B., Kulkarn, S. and Karunakar, P. (2010) Breast Self Examination. Knowledge, Attitude and Practice among Students in India. Indian Journal of Palliative Care, 1, 66-67.

[2] Globocan (2008) Cancer Incidence, Mortality and Prevalence. Worldwide. http://www.ncbi.nim.nih.gov

[3] Ganiyi, O. and Ganiyu, A. (2012) Epidemiology of Breast Cancer in Europe and Africa. Journal of Cancer Epidermiology, 2012, Article ID: 915610. http://dx.doi.org/10.1155/2012/915610

[4] Akarolo, S., Ogundiran, T. and Adebamowo, C. (2010) Emerging Breast Cancer Epidemic: Evidence from Africa. Breast Cancer Research, 20, S8.

[5] Adepeju, W. (2012) Are Cancer Cases Increasing in Nigeria? Home Health, 11, 6.

[6] Otunne, C. (2008) Breast Cancer: Causes and Therapies. CKC, Rex Press, Aba.

[7] Chiejina, A. (2011) Experts Make Case for Cancer Care and Management in Nigeria. http://www.academia.edu/4510582/PROJECT__CHAPTERS_ONE_TO_FIVE

[8] FRON (2007) Population Census. Federal Republic of Nigeria Official Gazette 24:94, Federal Government Printer (FGP 71/52007) 2500 24, B186, Lagos.

[9] Krejice, R.V. and Morgan, D.W. (1970) Determining Sample Size for Research Activities, Educational and Psychological Measurement. The NEA Research Bulletin, 30, 607-610.

[10] Oluwatosin, O. (2010) Assessment of Women's Risk Factors for Breast Cancer and Predictors of the Practice of BSE in Two Rural Areas in Ibadan, Nigeria. Cancer Epidemiology, 34, 425-428. http://dx.doi.org/10.1016/j.canep.2010.04.005

[11] Subramanian, P., Oranye, N.O., Masri, A.M., Taib, N.A. and Ahmad, N. (2013) Breast Cancer Knowledge and Screening Behaviour among Women with a Positive History: A Cross Sectional Study. Asian Pacific Journal of Cancer Prevention, 14, 6783-6790. http://www.ncbi.nilm.nih.gov/pubmed/24377606 